\title{
A PENALTY FUNCTION METHOD FOR COMPUTING CHEMICAL EQUILIBRIA
}

\author{
David J. KIRKNER \\ Department of Civil Engineering, University of Notre Dame, Notre Dame, IN 46556, U.S.A \\ and \\ HOWARD W. REEVES \\ Department of Civil Engineering, University of Michigan. Ann Arbor, MI 48109. U.S.A. \\ (Received 17 August 1987: revised 10 August 1988; received for publication 20 June 1989)
}

\begin{abstract}
A penalty function technique is developed as an alternative method for handling precipitationdissolution reactions in the equilibrium constant method of solving the batch chemical equilibrium problem. It is simple to incorporate into existing programs which do not handle precipitation-dissolution reactions. No variable eliminations need to be performed and the size of the system is always the same even as additional solids enter the problem. Two sample problems are presented to demonstrate the implementation of the method.
\end{abstract}

Key Words: Chemical equilibrium, Computation. Mathematics, Penalty function, Precipitation/ dissolution.

\section{INTRODUCTION}

There are many problems in geochemistry and geophysics where knowledge of the equilibrium state of a set of reacting chemical constituents is important. Since the 1940s and the pioneering work of Brinkley $(1946,1947)$ much progress has been made in developing efficient computational procedures to solve this problem with a variety of different applications in mind. A good review of different approaches and existing software for equilibrium calculations in aqueous systems is given by Nordstrom and others (1979).

There are two basic approaches to the equilibrium problem: the Gibb's energy minimization and the so-called equilibrium constant approach. For fairly large complex chemical systems, of interest in geochemical applications, the latter approach is desirable primarily because of the lack of thermodynamic data required for the former. This paper is concerned with only the equilibrium constant method. As a perusal of Nordstrom and others (1979) indicates, there are many available programs based on the equilibrium constant method. One reason that many programs have been and continue to be developed is that the database (the set of chemical constants which characterize the equilibrium state) required for large complex chemical systems is large and different applications require different databases.

Existing programs use various methods (of concern here is principally the Newton-Raphson method) to solve the nonlinear algebraic equations that govern the equilibrium calculation. The approaches differ in efficiency. However it could be argued that even for a large chemical system (e.g. 100 components) the number of equations involved do not pose much of a burden on modern computers. Compare, for instance, the computational effort required for the approximate solution of sets of nonlinear partial differential equations which may involve solving thousands of nonlinear algebraic equations. Thus if a program for equilibrium chemical calculations works, the relative efficiency might not seem important. However, a fairly new application has arisen in recent years which requires programs which are flexible and efficient. This application is modeling the transport of reacting solutes through porous media. Several general approaches to this problem have been advanced in the literature recently; for example Walsh and others (1984) and Kirkner, Theis, and Jennings (1984). Although each of these works solve the governing equations with a different algorithm, they possess the common feature of iterating between two sets of equations; one set contains in essence the discretized transport equations, and the second set contains the algebraic equations of chemical equilibrium at each nodal point in the domain. Thus in a typical simulation chemical equilibrium calculations may be performed at hundreds of iterations and time steps. The efficiency of the chemical equilibrium calculations is thus of considerable importance.

For systems involving only an aqueous phase the formulation of the nonlinear algebraic equations is standard and solution by Newton-Raphson iteration straightforward. Variants of this method and other nonlinear algebraic equation algorithms also have been employed (Morin, 1985). If a solid phase is present resulting from a precipitation-dissolution reaction, there are several approaches which have 
been employed in the literature. These different approaches will be reviewed herein and a new method utilizing a penalty function approach introduced. This modified penalty technique offers some insight into the solubility product as a constraint on the system and is simple to implement. Two sample calculations are presented to clarify the implementation of the method. This paper is basically an exposition of the method; much development work is required yet before its relative efficiency can be evaluated properly for large chemical systems.

For simplicity in presentation ideality is assumed in the following, that is concentrations of aqueous species are taken equal to activities. The algorithm presented is modified easily to use activity coefficients, however their inclusion in the presentation obscures the basic ideas.

\section{CHEMICAL EQUILIBRIUM IN HOMOGENEOUS AQUEOUS SYSTEMS}

As originally developed by Brinkley (1946), $N$ constituents of a homogeneous aqueous chemical system may be divided into $N_{\mathrm{c}}$ components and $N_{\mathrm{cx}}$ complexes. The number of components of a system is defined as the smallest number of substances required to determine the concentration of all species in the system. A component itself is a species in the system. Complexes are considered products in reactions where the components are the reactants. These reactions can be written

$$
\sum_{j=1}^{N_{i}} A_{1} \hat{c}_{j} \rightleftarrows \hat{x}_{i}\left(i=1,2, \ldots, N_{\mathrm{cx}}\right) .
$$

A specific example of these reactions is given for the $\mathrm{CaCO}_{3}$ system in Appendix 2. This sample problem is used later for some numerical results. In Equation (1) $\hat{c}_{1}$ (respectively $\hat{x}_{i}$ ) represents the chemical formula for component $j$ (respectively complex $i$ ). The $A_{i j}$ are the stoichiometric coefficients. The mathematical statement of equilibrium for each reaction in (1) is the law of mass action

$$
x_{i}=K_{i} \prod_{j=1}^{N_{c}} c_{j}^{A_{j}}\left(i=1, \ldots, N_{\mathrm{cx}}\right)
$$

where $c_{j}, x_{i}$ are the concentrations (moles per volume of solution) of components $\hat{c}_{j}$ and complexes $\hat{x}_{i}$, and $K_{i}$ is the equilibrium constant for the $i$ th reaction. The statement of conservation of mass for each component is

$$
u_{k}=c_{k}+\sum_{i=1}^{i_{i x}} A_{i k} x_{i}\left(k=1, \ldots, N_{c}\right),
$$

where $u_{k}$ is the prescribed total soluble concentration of component $k$. Substituting Equations (2) into (3) yields

$$
u_{k}=c_{k}+\sum_{i=1}^{N_{\mathrm{cx}}} A_{i k} K_{i} \prod_{j=1}^{N_{i}} c_{j}^{A_{1 j}}\left(k=1, \ldots, N_{c}\right) .
$$

Equation (4) represents $N_{\mathrm{s}}$ equations for the $N_{\mathrm{c}}$ unknowns $c_{k}, k=1,2, \ldots, N_{\mathrm{c}}$.

The solution of (4) by a Newton-Raphson iteration can be detailed easily by introducing a vector notation as follows. Let $\mathbf{u}$ be the vector with components $u_{k}$, c the vector with components $c_{k}$ and $\mathbf{f}(\mathbf{c})$ the vector with components

$$
f_{k}=\sum_{i=1}^{v_{c \mathrm{x}}} A_{i k} K_{i} \prod_{j=1}^{x_{c}} c_{j}^{A_{i j}}\left(k=1, \ldots N_{i}\right)
$$

Now define the vector $g(c)$ as

$$
\mathbf{g}(\mathbf{c})=\mathbf{c}+\mathbf{f}(\mathbf{c})-\mathbf{u}
$$

Then Equation (4) is equivalent to

$$
\mathbf{g}(\mathbf{c})=\mathbf{0}
$$

Let the $m+1$ st iterate of $\mathrm{c}$ be related to the $m$ th iterate by

$$
\mathbf{c}^{m+1}=\mathbf{c}^{m}+\Delta \mathbf{c}^{m}
$$

and evaluate $f\left(c^{m+1}\right)$ by using a first-order Taylor series

$$
\mathbf{f}\left(\mathbf{c}^{m+1}\right)=\mathbf{f}\left(\mathbf{c}^{m}\right)+\left(D f\left(\mathbf{c}^{m}\right)\right) \Delta \mathbf{c}^{m}
$$

where $D f(c)$ is the Jacobian matrix with components $\hat{c} f_{k} / \partial c_{j}$. Now evaluate (7) at the $m+1$ st iterate

$$
\begin{aligned}
\mathbf{g}\left(\mathbf{c}^{m+1}\right)= & \mathbf{c}^{m}+\Delta \mathbf{c}+\mathbf{f}\left(\mathbf{c}^{m}\right) \\
& +\left(D f\left(\mathbf{c}^{m}\right)\right) \Delta \mathbf{c}^{m}-\mathbf{u}=0
\end{aligned}
$$

Thus

$$
\begin{aligned}
\left(\mathbf{I}+D \mathbf{f}\left(\mathbf{c}^{m}\right)\right) \Delta \mathbf{c}^{m} & =-\left(\mathbf{c}^{m}+\mathbf{f}\left(\mathbf{c}^{m}\right)-\mathbf{u}\right) \\
& =-\mathbf{g}\left(\mathbf{c}^{m}\right)
\end{aligned}
$$

and

$$
\Delta \mathbf{c}^{\prime \prime}=-\left(\mathbf{I}+D \mathbf{f}\left(\mathbf{c}^{m}\right)\right)^{-1} \mathbf{g}\left(\mathbf{c}^{m}\right),
$$

where $I$ is the identity matrix. Equation (12) is solved repeatedly with $\mathbf{c}^{\text {nt+1}}$ updated according to (8). Iteration is stopped when $\left\|\mathbf{g}^{\boldsymbol{m}}\right\|$ is less than some prescribed tolerance, where $\|\cdot\|$ is any finite dimensional vector norm. The Newton-Raphson scheme (12) possesses second order convergence (Ortega and Rheinboldt, 1970). After the component concentrations are determined the complex concentrations are computed from (2).

\section{CHEMICAL EQUILIBRIUM WITH A SOLID PHASE}

A solid species, like the complexes, can be considered the product in a reaction where the components are the reactants

$$
\hat{p}_{i} \rightleftharpoons \sum_{k=1}^{N_{c}} B_{i k} \dot{c}_{k}\left(i=1, \ldots N_{,}\right)
$$

where $\hat{p}_{i}$ represents the chemical formula for solid $i$ and the $B_{i k}$ are stoichiometric coefficients. The equilibrium statement for (13) is, 


$$
K_{t}^{\mathrm{sO}}=\prod_{k=1}^{v i v} c_{k}^{B_{i k}}
$$

where $K_{i}^{\mathrm{SO}}$ is the solubility product. The concentration of the precipitate, $p_{i}$, does not occur in (14) because the activity of the solid is one.

The revised mass balance, to account for the solids, is written

$$
h_{k} \equiv g_{k}+\sum_{l=1}^{N_{s}} B_{l k} p_{l}=0\left(k=1 \ldots, N_{c}\right)
$$

where $g_{k}$ are the components of the vector $g$ introduced in Equation (7) and $h_{k}$ is introduced to represent the full set of equations and to simplify subsequent expressions. Equation (15) represents $N_{\mathrm{c}}$ equations for the $N_{\mathrm{c}}+N_{\mathrm{s}}$ unknowns $c_{i}$, $i=1,2, \ldots, N_{\mathrm{c}}$ and $p_{1}, i=1,2, \ldots, N_{\mathrm{s}}$. The remaining $N_{\mathrm{s}}$ equations are the mass action Equation (14) rewritten as

$$
q_{1} \equiv \prod_{k=1}^{N} c_{k}^{B_{i k}} / K_{i}^{S O}-1=0\left(i=1 \ldots N_{\mathrm{s}}\right) \text {. }
$$

Again, the $q$, are introduced to consolidate some of the mathematics to follow. It should be noted that Equation (16) can be written more properly as an inequality; less than or equal to zero. If a set of equilibrium concentrations can be obtained and $q$, is less than zero, then the solution is undersaturated and the $i$ th reaction in Equation (13) does not take place. If the equilibrium concentrations for the homogeneous system are such that $q_{1}$ is greater than zero, then the $i$ th reaction in Equation (13) will take place so that $q_{i}$ is zero. In this sense Equation (16) can be considered a set of inequality constraints on the system. In the development to follow, it is presumed that the reactions in Equation (13) are occurring.

Let $\mathbf{q}(\mathbf{c})$ be the vector with components defined in (16) and let B be the $N_{\mathrm{s}} \times N_{\mathrm{c}}$ matrix with components the stoichiometric coefficients, $B_{i k}$, and let $h$ and $\mathbf{p}$ be the vectors with components defined in (15). Then (15) and (16) may be rewritten compactly as

$$
\begin{gathered}
\mathbf{h}(\mathbf{c}, \mathbf{p})=\mathbf{c}+\mathbf{f}(\mathbf{c})+\mathbf{B}^{\mathrm{T}} \mathbf{p}-\mathbf{u}=\mathbf{0} \\
\mathbf{q}(\mathbf{c})=0 .
\end{gathered}
$$

Thus, according to (17) and (18), the formation of the solid species defined by the reaction (13) expands the size of the problem fron $N_{\mathrm{c}}$ unknowns to $N_{\mathrm{c}}+N_{\mathrm{s}}$ unknowns. Some researchers (e.g. Reed, 1982) proceed by solving (17) and (18) by a Newton-Raphson iteration. To reduce the size of the system, however, some take advantage of the fact that $h$ is linear in $\mathbf{p}$. Thus by linear combinations of the equations in (17) the precipitate concentrations may be eliminated reducing (17) to $N_{\mathrm{c}}-N_{\mathrm{s}}$ independent equations. Then along with (18) there are $N_{c}$ total equations for the components of $\mathrm{c}$. Once $\mathrm{c}$ is determined a subset of the equations in (17) may be used to solve for $\mathbf{p}$. This last step involves solving $N_{\mathrm{s}}$ linear equations. Thus this approach replaces the problem of $N_{\mathrm{c}}+N_{\mathrm{s}}$ nonlinear equations with $N_{\mathrm{c}}$ nonlinear equations and $N_{\mathrm{s}}$ linear equations. This method has been used recently by Walsh (1983). The elimination of $p$ as a primary unknown will be demonstrated here for the simple case of a single precipate. For $N_{\mathrm{s}}=1$ write (15) as

$$
h_{k}=c_{k}+f_{k}+B_{1 k} p_{1}-u_{k}=0 .
$$

Assume $B_{1 l}$ is nonzero, where $l$ is some integer between 1 and $N_{\mathrm{s}}$. Then

$$
\begin{gathered}
h_{k}-\left(\frac{B_{1 k}}{B_{11}}\right) h_{l}=c_{k}+f_{k}-u_{k}-\left(\frac{B_{1 k}}{B_{1 l}}\right) \\
\times\left(c_{l}+f_{l}-u_{l}\right)=0\left(k=1, \ldots N_{c}\right) . \\
(k \neq n)
\end{gathered}
$$

Equation (20) represent $N_{\mathrm{c}}-$ I equations; the remaining equation is from (16)

$$
q_{1}=\prod_{k=1}^{N} c_{k}^{B_{1 k}} / K_{i}^{\text {So }}-1=0 .
$$

Once (20) and (21) are solved for the component concentrations $c_{k}$, Equation (19) easily yields $p_{1}$.

An alternative approach reduces the size of the primary system even further. Rewrite (21) as

$$
q_{1}=\left(c_{l}^{B^{\prime \prime}}\right)\left(\prod_{\substack{k=1 \\ k \neq 1}}^{N_{i}} c_{k}^{B_{l k}}\right) / K_{1}^{50}-1=0 .
$$

Now solve (22) for $c_{1}$

$$
c_{t}=\left\{K_{i}^{\mathrm{So}} / \prod_{\substack{k=1 \\ k \neq 1}}^{v_{\mathrm{c}}} c_{k}^{B_{1 k}}\right\}^{\left(1 / \theta_{1,1}\right)}
$$

Substituting (23) into (20) yields $N_{c}-1$ equations for the $N_{\mathrm{c}}-1$ primary unknowns $c_{k}, k=1, \ldots, N_{\mathrm{c}}$ $(k \neq l)$. This last approach is utilized by Morel and Morgan (1972). In general they reduce the $N_{c}+N$ original equations to $N_{\mathrm{c}}-N_{\mathrm{s}}$ primary unknowns plus $N_{\mathrm{s}}$ secondary components determined from the primary set by equations of the form of (23) and finally the precipitates are determined by solving the linear set derived from (17). A drawback to this approach arises because Equation (16) really represents inequalities not equations, that is if $q_{t}<0$ then the corresponding reaction in (13) does not take place. Only when the solution is saturated, $q_{1}=0$, is $p_{i}$ formed. Thus, a priori it is not known normally which $p_{i}$ should be included in (17) with the corresponding constraint equation activated. The usual approach is to solve the system assuming no precipitates are present and then check all the solubility "constraints". If any of the constraints are violated, assume one solid is formed and resolve. Continue in this manner until a converged solution satisfies all solubility constraints. Thus the size of the problem is continually 
changing and the expressions for the terms in the coefficient matrix must be recalculated after every addition or deletion of a solid.

To recap, three basic approaches have been taken for handling the presence of precipitates. In the first (Reed, 1982, for example) the addition of $N_{5}$ solids increases the size of the system to $N_{\mathrm{c}}+N_{\mathrm{s}}$. After some manipulations. Walsh (1983) converts the size of the system to $N_{c}$; the original size without solids. Finally Morel and Morgan (1972), again after algebraic manipulations reduce the system to $N_{\mathrm{c}}-N_{\mathrm{s}}$ equations for the primary components. In all situations the resulting system of algebraic equations are solved by a Newton-Raphson iteration. It seems that a direct comparison between these approaches has not yet been made. Although solving a smaller set seems the most attractive, the accompanying algebraic manipulations must be considered as well as the conditioning of the resulting matrices.

In this paper a method is presented which similar to Walsh retains the system size as $N_{\mathrm{c}}$. However no transformation of the equation is required; an auxiliary matrix, which represents the contribution of the solids, is added to the coefficient matrix. An attractive feature is the ease with which precipitationdissolution reactions are included.

\section{PENALTY METHOD}

Equations (17) and (18) represent $N_{\mathrm{c}}+N_{\mathrm{s}}$ equations for the unknowns, $\mathbf{c}$ and $\mathbf{p}$. A distinctive feature of these equations is that they are not coupled in all the variables, that is the unknowns in the vector $p$ do not occur in the constraint Equation (18). The components of $\mathbf{p}$ are similar to Lagrange multipliers in a constrained minimization problem and may be eliminated as primary unknowns by a penalty function method similar to that employed in classical optimization. However a better motivation for the penalty function method is to consider the equilibrium concentration of the solid to be the limit of an expression obtained from the kinetic rate law for the dissolution reaction. This limit can be approached via some scalar parameter, not necessarily real time. This motivational argument for the penalty function approach is detailed in Appendix 1. Following this argument Equations (17) and (18) are replaced with

$$
h_{x}\left(c_{x}\right)=g\left(c_{x}\right)+\alpha B^{\top} \mathbf{q}\left(\mathbf{c}_{x}\right)=0,
$$

where $\alpha$ is termed the penalty parameter. Equation (24) is simply (17) with p replaced by $\alpha \mathbf{q}$. The designation $\mathbf{c}_{\mathbf{z}}$ indicates that the solution vector depends on $\alpha$. The following limits follow under suitable restrictions,

$$
\begin{gathered}
\left.\lim _{x \rightarrow x} c_{x}=c \text { [solution of }(17)(18)\right] \\
\lim _{z \rightarrow x} x \mathbf{q}\left(\mathbf{c}_{x}\right)=\mathbf{p} .
\end{gathered}
$$

It has been determined that sufficiently accurate answers are obtained by selecting a single large value of $x$. If double precision calculations are used, the range of values of $x$ which yield accurate answers is wide. This will be discussed further in the next section. From hereon the subscript $\boldsymbol{x}$ will be dropped but the dependence of the solution on $x$ should be kept in mind.

It is instructive to examine the Taylor series expansion of $h$ which yields the Newton-Raphson iteration

$$
\left(\mathbf{I}+D \mathbf{f}\left(\mathbf{c}^{m}\right)+x \mathbf{B}^{\top} D \mathbf{q}\left(\mathbf{c}^{m}\right)\right) \Delta \mathbf{c}^{m}=-\mathbf{h}\left(\mathbf{c}^{m}\right) \text {. }
$$

The difference between (27) and (11) (the iteration scheme for the system without solids) is simply the addition of the matrix $x \mathbf{B}^{\mathrm{T}} D \mathbf{q}\left(\mathbf{c}^{m}\right)$ to the coefficient matrix. Therefore programs which solve only homogeneous systems can be modified easily to account for precipitation-dissolution reactions. This is the primary purpose and the major advantage of the penalty approach.

The assembly of the additional matrix is a simple matter because.

$$
\frac{\dot{c} q_{k}}{c_{i}}=\frac{\left(q_{k}+1\right) B_{k j}}{c_{j}} .
$$

Thus

$$
\left(\mathbf{B}^{\top} D \mathbf{q}(\mathbf{c})\right)_{i j}=\frac{1}{c_{j}} \sum_{k=1}^{i_{j}} B_{k i} B_{k j}\left(q_{k}+1\right) .
$$

For computation purposes it must be noted that each $q_{1}$ is actually an inequality constraint on the system and therefore if $\varphi_{i}\left(\mathbf{c}^{\prime \prime}\right)$ is less than zero, that constraint is not included in the next iteration. That is, a constraint is only activated once it is violated. When there is more than one solid possible in a system, various approaches for activating the constraints are possible. For instance, Walsh (1983) and Morel and Morgan (1972) activate one constraint, completely solve the equilibrium problem and then check solubility products to see if any constraints are violated; if so, activate another constraint and reequilibrate. In the sample problems presented here, only one solid is present and the equilibrium solution ignoring the precipitation reaction violates the solubility constraint and thus it must be included as an equality constraint.

\section{EXAMPLE CALCULATIONS}

First, to demonstrate explicitly the calculations, consider the simple system governed by the following reactions

$$
\begin{aligned}
& \hat{c}_{1}+\hat{c}_{2} \rightleftarrows \hat{x}_{1} ; K_{1} \\
& \hat{p}_{1} \rightleftarrows \hat{c}_{2}+\hat{c}_{3} ; K_{1}^{\text {so }}
\end{aligned}
$$

The mass balances for the three components can be written, after substituting the mass action equations, as

$$
\begin{aligned}
& h_{1}=c_{1}+K_{1} c_{1} c_{2}-u_{1}=0, \\
& h_{2}=c_{2}+K_{1} c_{1} c_{2}-u_{2}=0, \\
& h_{3}=c_{3}+p-u_{3}=0,
\end{aligned}
$$


and the solubility constraint is

$$
q_{1}=c_{2} c_{3} / K_{1}^{\mathrm{SO}}-1=0 .
$$

Equations (32) and (33) are a specific example of (17) and (18). The penalty function formulation for this system corresponding to Equation (24) is

$$
\begin{aligned}
h_{1}(\mathbf{c})= & c_{1}+f_{1}(\mathbf{c})+x B_{1} q(\mathbf{c})-u_{1}=0 \\
= & c_{1}+K_{1} c_{1} c_{2}-u_{1}=0 \\
h_{2}(\mathbf{c})= & c_{2}+f_{2}(\mathbf{c})+x B_{2} q(\mathbf{c})-u_{2}=0 \\
= & c_{2}+K_{1} c_{1} c_{2}+x(1) \\
& \times\left(c_{2} c_{3} / K_{1}^{\mathrm{sO}}-1\right)-u_{2}=0 \\
h_{3}(\mathbf{c})= & c_{3}+f_{3}(\mathbf{c})+x B_{3} q(\mathbf{c})-u_{3}=0 \\
= & c_{3}+\alpha(1)\left(c_{2} c_{3} / K_{1}^{\mathrm{sO}}-1\right)-u_{3}=0 .
\end{aligned}
$$

where the fact that $B_{1}$ and $f_{3}$ are zero has been used. The matrices required for Equation (27) are (for the special situation of one solid, $\mathbf{B}$ and $D \mathbf{q}$ are vectors)

$$
\begin{aligned}
D \mathbf{f}(\mathbf{c}) & =\left[\begin{array}{lll}
\partial f_{1} / \partial c_{1} & \partial f_{1} / \partial c_{2} & \partial f_{1} / \partial c_{3} \\
\hat{c} f_{2} / \partial c_{1} & \partial f_{2} / \partial c_{2} & \partial f_{2} / \partial c_{3} \\
\partial f_{3} / \partial c_{1} & \partial f_{3} / \partial c_{2} & \partial f_{3} / \partial c_{3}
\end{array}\right], \\
& =\left[\begin{array}{lll}
K_{1} c_{2} & K_{1} c_{1} & 0 \\
K_{1} c_{2} & K_{1} c_{1} & 0 \\
0 & 0 & 0
\end{array}\right]
\end{aligned}
$$

and

$$
\begin{gathered}
\mathbf{B}^{T}=\left\{\begin{array}{l}
0 \\
1 \\
1
\end{array}\right\}, \\
D_{4}(\mathrm{c})=\left(0, c_{3}, c_{2}\right) / K^{\mathrm{so}} .
\end{gathered}
$$

Thus the Newton-Raphson iteration scheme for this sample problem corresponding to Equation (27) is
Using the data from Table 1, with $x=1000$, and inital conditions, $c_{1}^{0}=0.7402, c_{2}^{0}=3.1403, c_{3}^{0}=4.4$. yields the following system of equations for the first iteration.

$$
\begin{gathered}
\left(\left[\begin{array}{lll}
1 & 0 & 0 \\
0 & 1 & 0 \\
0 & 0 & 1
\end{array}\right]+\left[\begin{array}{ccc}
3.512 & 0.5922 & 0 \\
2.512 & 0.5922 & 0 \\
0 & 0 & 0
\end{array}\right]\right. \\
\left.+\left[\begin{array}{ccc}
0 & 0 & 0 \\
0 & 733.33 & 523.379 \\
0 & 733.33 & 523.379
\end{array}\right]\right)\left\{\begin{array}{l}
\Delta c^{0} 1 \\
\Delta c^{0} 2 \\
\Delta c^{0} 3
\end{array}\right\} \\
=-\left\{\begin{array}{l}
0.000006 \\
1302.866 \\
1302.866
\end{array}\right\} .
\end{gathered}
$$

Solution of this set yield $\Delta c^{0}=(0.163196 .-0.96786$, $-1.13105)$ and therefore $c^{1}=(0.90347 .2 .1724$. $3.26894)$. This procedure then is repeated until the residual vector $\mathbf{h}\left(\mathbf{c}^{m}\right)$ becomes sufficiently small. The final converged values for $\mathbf{c}$ and $\mathbf{p}$ are given in Table 1. Notice that accurate answers are obtained for $x$ ranging through many orders of magnitude. In each situation only three iterations were required, using double precision. The convergence criteria used was $\left\|\mathbf{h}^{\mathbf{m}}\right\|_{2}<10^{-5}\left\|\mathbf{h}^{0}\right\|_{2} ;$ where $\left\|\mathbf{h}^{m}\right\|_{2}$ is the square root of the sum of the squares of the components of $h$ at the $m$ th iterate. For $\alpha>10^{13}$ the accuracy deteriorates due to ill-conditioning of the matrix.

The second example, although rather simple, is more realistic. The problem is to determine the equilibrium composition of a solution to which $10^{-3}$ moles $/ \mathrm{l}$ of $\mathrm{CaCO}_{3}$ is added. This example is taken from Appendix 2 of Westall, Zachary, and Morel (1976). The system consists of three components, six

$$
\left\langle\left[\begin{array}{lll}
1 & 0 & 0 \\
0 & 1 & 0 \\
0 & 0 & 1
\end{array}\right]+\left[\begin{array}{ccc}
K_{1} c_{2}^{m} & K_{1} c_{1}^{m} & 0 \\
K_{1} c_{2}^{m} & K_{1} c_{1}^{m} & 0 \\
0 & 0 & 0
\end{array}\right]+\frac{\alpha}{K_{1}^{50}}\left\{\begin{array}{l}
0 \\
1 \\
1
\end{array}\right\}\left(\begin{array}{lll}
0 & c_{3}^{m} & \left.c_{2}^{m}\right)
\end{array}\right)\left\{\begin{array}{l}
\Delta c_{2}^{m} \\
\Delta c_{2}^{m} \\
c_{3}^{m} \\
3
\end{array}\right\}=\left\{\begin{array}{l}
h_{1}\left(\mathrm{c}^{m}\right) \\
h_{2}\left(\mathrm{c}^{m}\right) \\
h_{3}\left(\mathrm{c}^{m}\right)
\end{array}\right\} . \quad(38)\right.
$$

Table 1. Results for example problem No. 1

\begin{tabular}{|c|c|c|c|c|}
\hline \multicolumn{5}{|c|}{ Approximate Solutions } \\
\hline $\log \alpha$ & $c_{1}$ & $c_{2}$ & $c_{3}$ & $\mathrm{p}$ \\
& & & & \\
0 & .943 & 2.196 & 3.254 & 1.146 \\
1 & .9926 & 2.024 & 3.032 & 1.368 \\
2 & .9992 & 2.002 & 3.003 & 1.397 \\
3 & .9999 & 2.000 & 3.000 & 1.399 \\
4 & .9999 & 2.000 & 3.000 & 1.399 \\
5 & 1.000 & 2.000 & 3.000 & 1.400 \\
\hline
\end{tabular}

Data: $K_{1}=0.80, K^{50}=6.00, u_{1}=2.6, u_{2}=5.0, u_{3}=4.4$.

Exact solution: $c_{1}=1.0, c_{2}=2.0, c_{3}=3.0, p=1.4$.

Initial guess: $c_{1}^{0}=0.7402, c_{2}^{0}=3.1403, c_{3}^{0}=4.40$, from solution assuming no solid. 
Table 2. Data for calcium carbonate sample problem

\begin{tabular}{|l|c|c|c|c|}
\cline { 2 - 5 } & $\dot{c}_{1}=\mathrm{Ca}^{2}$ & $\dot{c}_{2}=\mathrm{H}^{\cdot}$ & $\dot{c}_{3}=\mathrm{CO}_{3}{ }^{2-}$ & $\log \mathrm{K}_{\mathrm{i}}$ \\
\hline$\dot{x}_{1}=\mathrm{CaCO}_{3}(\mathrm{aq})$ & 1 & 0 & 1 & 3.0 \\
$\dot{x}_{2}=\mathrm{CaHCO}_{3}{ }^{*}$ & 1 & 1 & 1 & 11.6 \\
$\dot{x}_{3}=\mathrm{CaOH}^{*}$ & 1 & -1 & 0 & -12.2 \\
$\dot{x}_{4}=\mathrm{HCO}_{3}{ }^{-}$ & 0 & 1 & 1 & 10.2 \\
$\dot{x}_{5}=\mathrm{H}_{2} \mathrm{CO}_{3}$ & 0 & 2 & 1 & 16.5 \\
$\dot{x}_{6}=\mathrm{OH}^{-}$ & 0 & -1 & 0 & -14.0 \\
\hline
\end{tabular}

A matrix

\begin{tabular}{|l|l|l|l|l|}
\cline { 2 - 5 } \multicolumn{1}{c|}{} & $\dot{c}_{1}$ & $\dot{c}_{2}$ & $\dot{c}_{3}$ & $\log \mathrm{K} \mathrm{Y}^{\prime}$ \\
\hline$\dot{p}_{1}=\mathrm{CaCo}_{3}(\mathrm{~s})$ & 1 & 0 & 1 & 8.3 \\
\hline
\end{tabular}

B matrix

Prescribed concentrations: $u_{1}=10^{-3} \mathrm{M} / 1, u_{2}=0, u_{3}=10^{-3} \mathrm{M} / \mathrm{l}$.

N.B.: $\mathrm{Ca}(\mathrm{OH})_{2}(\mathrm{~s})$ is not considered in this sample problem. Its solubility constraint is not violated, however, by the final solution.

aqueous complexes, and one solid. The data, that is the stoichiometric coefficients $A_{i j}$ and $B_{i j}$, the equilibrium constants, and the total component concentration in moles/l of each component are given in Table 2. The solution with and without the solubility constraint (expressed as - log concentration) obtained by the penalty function method described herein is given in Table 3 . It should be noted that the solution required six iterations (double precision calculations) when using as initial guess for the component concentrations the equilibrium solution assuming no solid present. The convergence criteria used was the same as in the first problem. Of course convergence of $\left\|\mathbf{h}^{m}\right\|_{2}$ does not imply $q_{1} \sim 0$. However for $10^{2}<\alpha<10^{8}, q_{1}$ always is $<10^{-5}$. Thus the method works, for this problem, through a wide range of penalty parameters. Details of the calculation for the first iteration are provided in Appendix 2.

\section{COMPUTER PROGRAM}

Appendix 3 contains the FORTRAN program PENALTY, which will perform the calculations described in this paper. The program has been run using Microsoft FORTRAN on a Macintosh Plus. All documentation required is in the program. Variable definitions in the program follow closely the notation in the paper. Following the program are the input and output for the two sample problems discussed here.

\section{DISCUSSION}

The penalty function method presented here is an alternative method for incorporating precipitationdissolution reactions in the equilibrium constant method for solving the chemical equilibrium problem. From a programming viewpoint the method is simple to incorporate into existing codes which do not hand-

Table 3. Results for calcium carbonate sample problem, with and without solid

\begin{tabular}{|c|c|c|}
\hline Species & $\begin{array}{c}\text { no solid } \\
-\log \left[\mathrm{x}_{i}\right]\end{array}$ & $\begin{array}{c}\text { with } \mathrm{CaCO}_{3}(\mathrm{~s}) \\
-\log \left[\mathrm{x}_{i}\right]\end{array}$ \\
\hline $\mathrm{Ca}^{2 \cdot}$ & 3.163 & 3.915 \\
$\mathrm{H}^{\cdot}$ & 10.413 & 9.9066 \\
$\mathrm{CO}_{3}^{2-}$ & 3.364 & 4.384 \\
$\mathrm{CaCO}_{3}$ & 3.526 & 5.299 \\
$\mathrm{CaHCO}_{3}{ }^{\circ}$ & 5.339 & 6.6066 \\
$\mathrm{CaOH}^{\cdot}$ & 4.950 & 6.208 \\
$\mathrm{HCO}_{3}{ }^{\circ}$ & 3.576 & 4.091 \\
$\mathrm{H}_{2} \mathrm{CO}_{3}$ & 7.689 & 7.698 \\
$\mathrm{OH}^{\cdot}$ & 3.587 & 4.093 \\
$\mathrm{CaCO}_{3}(\mathrm{~s})$ & - & 3.059 \\
\hline
\end{tabular}

Answers obtained with $x=100$. Solution of $-\log$ concentration is accurate to 4 significant figures for $10^{2}<$ $x<10^{8}$. 
le precipitation-dissolution reactions. Also no variable eliminations need to be performed and the size of the system always is the same; even as additional solids enter the problem. The efficiency of this technique relative to existing methods can be studied only with particular applications in mind, because the conditioning of the matrices surely plays a role.

It also should be mentioned that there are extensions of this method worthy of examination. For instance the so-called augmented Lagrangian methods (Fortin and Glowinski, 1982) may prove effective.

A study is currently underway to compare the various approaches which have been discussed herein.

Acknowledgment-The work presented in this paper was supported by grant DE-AC02-79EVI0253, from the Ecological Research Division. Office of Energy Research. U.S. Department of Energy to the University of Notre Dame.

\section{REFERENCES}

Brinkley, S. R., 1946. Note on the conditions of equilibrium for systems of many constituents: Jour. Chem. Phys., v. 14. p. 563-564.

Brinkley, S. R.. 1947, Calculation of the equilibrium composition of systems of many constituents: Jour. Chem. Phys., v. 15, p. 107-110.

Fortin. M., and Glowinski, R., 1982, Augmented Lagrangian methods: applications to the numerical solution of boundary value problems: Elsevier Science Publ. New York, 1982. $340 \mathrm{p}$.

Kirkner, D. J., Theis, T. L., and Jennings, A. A., 1984, Multicomponent solute transport with sorption and soluble complexation: Advances in Water Resources, v. 7 , p. 120-125.

Morel. F., and Morgan. J., 1972, A numerical method for computing equilibria in aqueous chemical systems: Environmental Science and Technology, v. 6, p. 58-67.

Morin, K. A., 1985, Simplified explanations and examples of computerized methods for calculating chemical equilibrium in water: Computers \& Geosciences, v. 11 , no. 4, p. $409-416$.

Nordstrom, D. K., Plummer, L. N., Wigley, T. M. L., Wolery. T. J., Ball, J. W., Jenne, E. A., Bassett, R. L., Crerar, D. A., Florence, T. B., Fritz, B., Hoffman, M., Holdren, G. R., Jr., Lafon. G. M., Mattigod, S. V., McDuff, R. E., Morel, F., Reddy, M. M., Sposito, G., and Thrailkill, J., 1979. A comparison of computerized chemical models for equilibrium calculations in aqueous systems, in Jenne, E. A. ed. Chemical modeling in aqueous systems: Am. Chemical Society, Washington, D.C., p. 857-892.

Ortega. J. M., and Rheinboldt, W. C., 1970, Iterative solution of nonlinear equations in several variables: Academic Press, New York, 502 p.

Reed, M. H., 1982, Calculation of multicomponent chemical equilibria and reaction processes in systems involving minerals, gases and an aqueous phase: Geochimica et Cosmochimica Acta, v. 46. p. 513-528.

Walsh, M. P., 1983, Geochemical flow modeling: unpubl. doctoral dissertation. Univ. Texas-Austin. 502 p.

Walsh, M. P., Bryant, S. L.. Schechter, R. S., and Lake, L. W., 1984, Precipitation and dissolution of solids attending flow through porous media: AICHE Jour., v. 30, p. 317-328.

Westall, J. C., Zachary, J. L., and Morel, F. M. M., 1976 , MINEQL-A computer program for the calculation of chemical equilibrium composition of aqueous systems: Tech. Note No. 18. Massachusetts Inst. of Technology, Dept. of Civil Engineering. $91 \mathrm{p}$

\section{NOMENCLATURE}

$A_{1 j}=$ Stoichiometric coefficient for aqueous phase complexation reaction

$B_{i j}=$ Stoichiometric coefficient for precipitation reactions

$\hat{c}_{1}=$ Chemical formula of component $j$

$c_{1}=$ Concentration of component $j$ (moles per unit volume of solution)

$k_{\mathrm{b}}=$ Backward reaction rate constant

$k_{\mathrm{r}}=$ Forward reaction rate constant

$K,=$ Equilibrium constant for the $i$ th aqueous phase complexation reaction

$K_{i}^{\text {so }}=$ Solubility product governing $i$ th precipitation reaction

$N=$ Total number of constituents in the aqueous system

$N_{\mathrm{c}}=$ Number of components

$N_{\mathrm{x}}=$ Number of complexes

$N_{s}=$ Number of precipitated solids

$\hat{p}_{1}=$ Chemical formula of precipitate $i$

$p_{1}=$ Concentration of precipitate $i$ (moles per unit volume of solution)

$q_{1}(\mathbf{c})=$ Constraint equation for $i$ th precipitation reaction

$\dot{x}_{1}=$ Chemical formula of complex $i$

$x_{t}=$ Concentration of complex $i$ (moles per unit volume of solution)

$\alpha=$ Penalty parameter

$\Delta=$ Discrete increment in a variable

\section{Matrix and vector quantities}

$\mathbf{A}=$ Stoichiometric matrix for aqueous phase complexation reactions

B = Stoichiometric matrix for precipitation reactions

$D f(c)=$ Jacobian matrix with members $\partial f_{i} / \partial c$

$I$ = Identity matrix

$c=$ Vector of component concentrations

$f(c)=$ Vector valued function of component vector $c$

$\mathbf{g}(\mathbf{c})=$ Vector of conservation of mass expressions for each component

$\mathbf{h}(\mathbf{c})=$ Vector of revised conservation of mass expressions to account for precipitation reactions

$\mathbf{p}=$ Vector of precipitation concentrations

$\mathbf{q}(\mathbf{c})=$ Vector of constraint equations for precipitation reactions

$\mathbf{u}=$ Vector of total soluble component concentrations

\section{APPENDIX 1}

The penalty function approach can be motivated by the following arguments. Consider, for example, the chemical kinetic rate expressions for the reaction of Equation (31),

$$
\frac{\mathrm{d} p_{1}}{\mathrm{~d} t}=k_{\mathrm{b}} c_{2} c_{3}-k_{\mathrm{i}}
$$


where $t$ is time, $k_{\mathrm{f}}$ and $k_{\mathrm{b}}$ are the forward and backward rate constants respectively and the activity of the solid is taken as one. We assume order corresponds to stoichiometry. Equation (Al) also can be written

$$
\frac{\mathrm{d} p_{1}}{\mathrm{~d} t}=k_{\mathrm{f}}\left(c_{2} c_{3} / K^{\mathrm{so}}-\mathrm{I}\right)
$$

where $K^{\mathrm{SO}}=k_{\mathrm{f}} / k_{\mathrm{b}}$ is the equilibrium constant for the reaction. We define the expression in the parentheses to be $q_{1}$ and rewrite (A2) as

$$
\frac{\mathrm{d} p_{1}}{\mathrm{~d} t}=k_{\mathrm{r}} q_{1}(t)
$$

We know that at equilibrium $\mathrm{d} p_{1} / \mathrm{d} t$ is zero and therefore $q_{1}(t)$ is zero at equilibrium also. Additionally, because the concentrations must be positive, the function $q_{1}(t)$ always is $\geqslant-1$ and also is bounded above because $\mathrm{d} p_{1} / \mathrm{d} t$ must be finite. With these properties of $q_{1}$ in mind, we now integrate Equation (A3) yielding

$$
p_{1}(T)=k_{\mathrm{f}} \int_{0}^{T} q_{1}(t) \mathrm{d} t,
$$

assuming no solid is initially present. $T$ is some specific time. Using the mean value theorem. Equation (AS) can be written

$$
p_{1}(T)=k_{\mathrm{f}} T \overline{q_{1}(T)}
$$

where $\overline{q_{1}(T)}$ is the mean value of $q_{1}$ over the interval $(0, T)$. Taking the limit of both sides of Equation (A5) as $T$ goes to infinity and noting that $p_{1}(T)$ is bounded. implies

$$
\lim _{r \rightarrow x} \overline{q_{1}(T)}=0
$$

But from the properties of $q_{1}(t)$ as discussed,

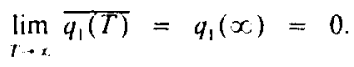

Thus as $T$ goes to infinity, $k_{\mathrm{f}} T \overline{q_{1}(T)}$ has a limit which is the equilibrium value of $p_{1}$, and $\overline{q_{1}(T)}$ approaches the equilibrium value of $q_{1}(l)$. Because $T$ only needs to be considered as a parameter and not as real time, the equitibrium value of $p_{1}$ can be written as

$$
p_{1}=\lim _{x \rightarrow \infty} x q_{1}(x)
$$

which basically is Equation (26).

Thus, to recap, the equilibrium value of the precipitate concentration may be replaced with the limit of the kinetic rate expression [written as in Eq. (AS)] as some positive, real paramenter goes to infinity.

Although Equation (A8) is simply a consequence of the transient system, normally not exploitable, herein it is determined to be a useful artifice for solving the equilibrium problem.

\section{APPENDIX 2}

\section{$\mathrm{CaCO}$, Example}

$$
\begin{aligned}
& \text { Components } \\
& \dot{c}_{1}=\mathrm{Ca}^{2+} \\
& \dot{c}_{2}=\mathrm{H}^{+} \\
& \dot{c}_{3}=\mathrm{CO}_{3}^{2-}
\end{aligned}
$$

Reaction: aqueous

$$
\begin{aligned}
& \text { Complexes } \\
& \dot{x}_{1}=\mathrm{CaCO}_{3}(\mathrm{aq}) \\
& \dot{x}_{2}=\mathrm{CaHCO}_{3} \\
& \dot{x}_{3}=\mathrm{CaOH}^{+} \\
& \dot{x}_{4}=\mathrm{HCO}_{3}^{-} \\
& \dot{x}_{5}=\mathrm{H}_{2} \mathrm{CO}_{3} \\
& \dot{x}_{6}=\mathrm{OH}^{-} .
\end{aligned}
$$

Solid

$\dot{p}_{1}=\mathrm{CaCO}_{3}(s)$

$\mathrm{Ca}(\mathrm{OH})_{2}(\mathrm{~s})$ not considered.

$$
\begin{aligned}
\mathrm{Ca}^{2+}+\mathrm{CO}_{3}^{--} & \rightleftarrows \mathrm{CaCO}_{3} \\
\mathrm{Ca}^{2+}+\mathrm{CO}_{3}^{-2} & +\mathrm{H}^{+} \rightleftarrows \mathrm{CaHCO}_{3}^{+} \rightleftarrows \mathrm{CaOH}^{+} \\
\mathrm{Ca}^{2+}+\mathrm{OH}^{-} & \rightleftarrows \mathrm{HCO}_{3}^{-} \\
\mathrm{H}^{+}+\mathrm{CO}_{3}^{-} & \rightleftarrows \mathrm{HCO}_{3}^{+}+\mathrm{CO}_{3}^{-} \rightleftarrows \mathrm{H}_{2} \mathrm{CO}_{3}
\end{aligned}
$$


Reactions: solid phase

Imposed concentrations

$u_{1}=10^{-3} \mathrm{M} / 1$

$u_{2}=0.0 \mathrm{M} / 1$

$u_{3}=10^{-3} \mathrm{M} / 1$
$\mathrm{Ca}(\mathrm{OH})_{2}(\mathrm{~s}) \rightleftharpoons \mathrm{Ca}^{2+}-2 \mathrm{H}^{+}$

$\mathrm{CaCO}_{3}(\mathrm{~s}) \rightleftarrows \mathrm{Ca}^{2+}+\mathrm{CO}_{3}^{2-}$

This system written in the form of Equation (32) is,

$$
\begin{gathered}
h_{1}(\mathbf{c})=c_{1}+K_{1} c_{1} c_{3}+K_{2} c_{1} c_{2} c_{3}+K_{3} c_{1} c_{2}^{-1}+x\left(\frac{c_{1} c_{3}}{K_{1}^{50}}\right)-1-u_{1}=0.0 . \\
h_{2}(\mathbf{c})=c_{2}+K_{2} c_{1} c_{2} c_{3}-K_{3} c_{1} c_{2}^{-1}+K_{4} c_{2} c_{3}+2 K_{3} c_{2}^{3} c_{3}-K_{6} c_{2}^{-1}-u_{2}=0.0 . \\
h_{3}(\mathbf{c})=c_{3}+K_{1} c_{1} c_{3}+K_{2} c_{1} c_{2} c_{3}+K_{4} c_{2} c_{3}+K_{5} c_{2}^{2} c_{3}+z\left(\frac{c_{1} c_{3}}{K_{1}^{50}}-1\right)-u_{3}=0.0 .
\end{gathered}
$$

The Newton-Raphson form. Equation (33), for this system is,

$$
\begin{aligned}
& \left(\left[\begin{array}{lll}
1 & 0 & 0 \\
0 & 1 & 0 \\
0 & 0 & 1
\end{array}\right]+\left[\begin{array}{ll}
\left(K_{1} c_{3}^{m}+K_{2} c_{2}^{m} c_{3}^{m}+K_{3}\left(c_{2}^{m}\right)^{-1}\right) & \left(K_{2}^{m} c_{1}^{m} c_{3}^{m}-K_{2}^{m} c_{1}^{m} c_{3}^{m}-K_{3}^{m}\left(c_{2}^{m}\right)^{-2}\right) \\
\left(K_{2} c_{2}^{m} c_{3}^{m}-K_{3}\left(c_{2}^{m}\right)^{-1}\right) & \left(K_{2} c_{1}^{m} c_{3}^{m}+K_{3} c_{1}^{m}\left(c_{2}^{m}\right)^{-2}+K_{4} c_{3}^{m}+4 K_{5} c_{2}^{m} c_{3}^{m}+K_{6}\left(c_{2}^{m}\right)^{-2}\right) \\
\left(K_{1} c_{3}^{m}+K_{2} c_{2}^{m} c_{3}^{m}\right) & \left(K_{2} c_{1}^{m} c_{3}^{m}+K_{1} c_{3}^{m}+K_{5}\left(c_{2}^{m}\right)^{2}\right)
\end{array}\right.\right. \\
& \left.\begin{array}{l}
\left(K_{1} c_{1}^{m}+K_{2}\left(c_{1}^{m} c_{2}^{m}\right)\right. \\
\left(K_{2} c_{1}^{\prime \prime} c_{2}^{m}+K_{4} c_{2}^{m}+2 K_{5}\left(c_{2}^{m}\right)^{2}\right) \\
\left(K_{1} c_{1}^{m}+K_{2} c_{2}^{m}+K_{4} c_{2}^{m}+K_{5}\left(c_{2}^{m}\right)^{2}\right)
\end{array}\right]+\frac{x}{K_{1}^{s 0}}\left\{\begin{array}{l}
1 \\
0 \\
1
\end{array}\right\}\left(\begin{array}{lll}
c_{3} & 0 & \left.c_{1}\right)
\end{array}\right]\left\{\begin{array}{l}
\Delta c_{1}^{m} \\
\Delta c_{2}^{m} \\
\Delta c_{3}^{m}
\end{array}\right\}=\left\{\begin{array}{l}
h_{1}\left(c^{m}\right) \\
h_{2}\left(c^{m}\right) \\
h_{3}\left(c^{m}\right)
\end{array}\right\} .
\end{aligned}
$$

The matrices arising from Equation (33) using the data given in Tables 2 and 3 with $\alpha=100$

$$
\left(\left[\begin{array}{lll}
1 & 0 & 0 \\
0 & 1 & 0 \\
0 & 0 & 1
\end{array}\right]+\left[\begin{array}{ccc}
10^{-0.3415} & -10^{5.2358} & 10^{-0.1564} \\
-10^{-2.0132} & 10^{7.145} & 10^{-0.1055} \\
10^{-0.3573} & 10^{6.8439} & 10^{0.1173}
\end{array}\right]+\left[\begin{array}{ccc}
10^{6.936} & 10^{7.137} \\
0 & 0 & 0 \\
10^{6.936} & 0 & 10^{7.137}
\end{array}\right]\right)\left\{\begin{array}{l}
\Delta c_{1} \\
\Delta c_{2} \\
\Delta c_{3}
\end{array}\right\}=-\left\{\begin{array}{l}
10^{3.7656} \\
10^{-6.2368} \\
10^{3.7656}
\end{array}\right\}
$$

The solution for the first increment is then

$$
\Delta c^{0}=\left\{\begin{array}{l}
-10^{-3.1854} \\
-10^{-130572} \\
-10^{-5.0054}
\end{array}\right\} \text { and thus, } c^{1}=\left\{\begin{array}{l}
10^{-4462} \\
10^{-10.414} \\
10^{3.374}
\end{array}\right\}
$$

\section{APPENDIX 3}

\section{Program PENALTY}

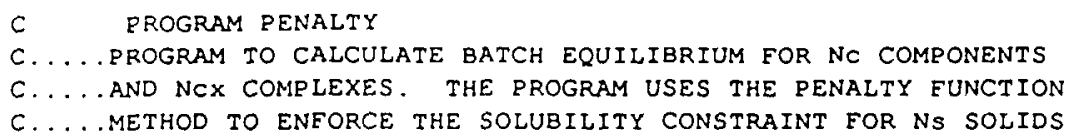


C... FORMED BY THE PRECIPITATION OF COMPONENTS. ALL DATA IS C..... INPUT BY THE USER, EITHER EROM THE KEYBOARD OR DATA EILES, C.... DATA FILES ARE CREATED IF THE KEYBOARD IS USED TO ENTER C.... DATA INITIALLY.

C.... THE PENALTY FUNCTION PROCEDURE MAY BE USED IN OTHER BATCH C.... EQUILIBRIUM PROGRAMS IN A MANNER SIMILAR TO THAT EMPLOYED C.... HERE.

C....VVARIABLE LIST:

$A(I, J)=$ STOICHIOMETRIC MATRIX EOR COMPLEXES, (INTEGER), ALPHA $=$ PENALTY PARAMETER

$B(I, J)=$ STOICHIOMETRIC MATRIX FOR PRECIPITATES, (INTEGER), $C(I)=$ CONCENTRATION OE COMPONENT I, CMPLX (I) = NAME OF COMPLEX I, (CHARACTER*B), $\operatorname{COMP}(I)=$ NAME OF COMPONENT I, (CHARACTER $* 8)$, DELTA = CONVERGENCE CRITERIA, NORM(DC) $/$ NORM $(D C O)<D E L T A$, $D F(I, J)=J A C O B I A N$ MATRIX FOR COMPLEXES, DF $(I, J)=d F(I) / d C(J)$ $D Q(I, J)$ = JACOBIAN MATRIX EOR PRECIPITATES * B(TRANSPOSE), $F(I)=$ FUNCTION REPRESENTING MASS OE COMPONENT I IN COMPLEXED FORMS,

$G(I)=$ RIGHT HAND SIDE OF MATRIX EQUATION $G(I)=-(C(I)+F(I)-U(I)+$ PENALTY TERMS IF NEEDED), IBATCH $=$ FLAG VARIABLE,

IF 0 - SOLVE EQUIBRIUM PROBLEM WITHOUT SOLID AND THEN CHECK SOLUBILITY CONSTRAINT IF NOT O-CHECK SOLUBILITY CONSTRAINT FOR INITIAL GUESS AND EACH ITERATION THEREAFTER, ITER = COUNTER FOR NUMBER OF ITERATIONS, ITERMAX = MAXIMUM NUMBER OF ITERATIONS ALLOWED, ITABLE = COUNTER USED IN OUTPUT TO STORE NUMBER OF STOICHIOMETRIC MATRIX TABLES REQUIRED, JCOMP = INTEGER READ IN TO GIVE COMPONENT NUMBER IN COMPLEX, JSTOICH = STOICHIOMETRIC COEFEICIENT OF COMPONENT JCOMP IN THE CURRENT COMPLEX,

NC = NUMBER OE COMPONENTS, NCX = NUMBER OF COMPLEXES, NCOMP $(I)=$ NUMBER OF COMPONENTS IN COMPLEX I, NPPT(I) = NUMBER OF COMPONENTS IN PRECIPITATE I, NS = NUMBER OF SOLIDS, P - "CONCENTRATION" OE PRECIPITATE, PRECIP = LOGICAL VARIABLE, USED TO INDICATE IF THE SOLUBILITY CONSTRAINT IS VIOLATED,

$\operatorname{PPT}(I)=$ NAME OF PRECIPITATE I, (CHARACTER*8), PROD - VARIABLE USED TO STORE AND CALCULATE PRODUCTS, $Q(I)=$ SOLUBILITY CONSTRAINT FOR SOLID I, RK(I) = EQUILIBRIUM COEFEICIENT FOR COMPLEX I, RKSO(I) - SOLUBILITY PRODUCT FOR PRECIPITATE I, RLHS $(I, J)$ - LEET HAND SIDE MATRIX, $U(I)$ - TOTAL PRESCRIBED (ANALYTICAL) CONCENTRATION OF COMPONENT I,

$X=$ CONCENTRATION OF COMPLEX.

REQUIRED SUBROUTINES :

MATRIX SOLVER, FOR THIS PROGRAM THE SOLVER GAUSS() IS USED.

REQUIRED FILES:

8 - FILE TO STORE INPUT DATA. THIS FILE IS CREATED IF THE KEYBOARD IS USED TO INPUT DATA OR IS THE EILE USED IF INPUT EROM A FILE IS SELECTED. THE NAME OF THE FILE IS INPUT BY THE USER AND IS STORED IN THE VARIABLE INDATA, (CHARACTER*15)

10 - EILE TO WRITE OUTPUT DATA. THE EILE NAME IS ENTERED BY THE USER AND STORED IN THE VARIABLE OUTPUT, (CHAR*15)

IMPLICIT REAL $8(A-H, O-Z)$

CHARACTER 8 COMP (10), CMPLX $(10)$, PPT (10)

CHARACTER 15 INDATA, OUTPUT

INTEGER A $(10,10), B(10,10)$

LOGICAL PRECIP, BATCH 
DIMENSION $C(10), F(10), G(10), \operatorname{TITLE}(20)$

DIMENSION RK(10), RKSO $(10), \operatorname{NCOMP}(10), \operatorname{NPPT}(10), \mathrm{U}(10)$

DIMENSION DE $(10,10), Q(10), D Q(10,10), \operatorname{RLHS}(10,10)$

C

C....READ IN DATA - UNIT 9 IS TERMINAL FOR MICROSOFT FORTRAN

C. . . GET OUTPUT EILE NAME AND OPEN EILE AS NEW

C.....EXISTING FILES WITH THE SAME NAME ARE FIRST DELETED

WRITE $(9, *) '$ ENTER THE NAME OF A FILE TO WRITE OUTPUT'

$\operatorname{READ}(9, *)$ OUTPUT

OPEN (10, EILE =OUTPUT, STATUS = ' NEW')

C.... DETERMINE INPUT TYPE, FROM FILE OR KEYBOARD

WRITE $(9, *)$ " TYPE "O" TO ENTER DATA FROM A EILE'

WRITE $(9, *)$ ' OR "I" TO ENTER DATA FROM THE KEYBOARD'

$\operatorname{READ}(9, *)$ DATAIN

IF (DATAIN .EQ. O)GO TO 50

C.... DATA INPUT FROM THE KEYBOARD

C. . . ENTER TITLE

WRITE $(9, *)$ ' ENTER TITLE (ONE LINE)'

READ $(9,1000)$ TITLE

C. . . ENTER PENALTY PARAMETER AND CONVERGENCE CRITERIA

WRITE $(9, *)$ ' ENTER PENALTY PARAMETER, ALPHA'

WRITE $(9, *)$ ' AND CONVERGENCE CRITERIA'

$\operatorname{READ}(9, *)$ ALPHA, DELTA

C. . . . ENTER NUMBER OE COMPONENTS, COMPLEXES AND PRECIPITATES

WRITE $(9, *)$ ' ENTER THE NUMBER OF COMPONENTS, NC'

WRITE $(9, *)$ ' THE NUMBER OF COMPLEXES, NCX'

WRITE $(9, *)$ ' AND THE NUMBER OE PRECIPITATED SOLIDS, NS'

$\operatorname{READ}(9, *) N C, N C X, N S$

C.... Get THE NAMES OF THE COMPONENTS, COMPLEXES AND SOLIDS

DO $10 \mathrm{I}=1, \mathrm{NC}$

WRITE $(9, *)$ ' ENTER THE NAME OE COMPONENT', I

$10 \operatorname{READ}(9, *) \operatorname{COMP}(\mathrm{I})$

DO $11 I=1, N C X$

WRITE $(9, *)$ ' ENTER THE NAME AND EQUILIERIUM CONSTANT FOR COMPLEX' $\&, I$

$11 \operatorname{READ}(9, *) \operatorname{CMPLX}(I), \operatorname{RK}(I)$

DO $12 \quad I=1, N S$

WRITE $(9, *)$ ' ENTER THE NAME AND SOlUbility PRODUCT FOR PRECIPITATE' $\&, I$

$12 \operatorname{READ}\left(9,{ }^{\star}\right) \operatorname{PPT}(I), \operatorname{RKSO}(\mathrm{I})$

C.... GET THE STOICHIOMETRIC MATRICES A AND B.

C.... SET ALL ENTRIES TO ZERO AND HAVE USER ENTER NON-ZERO ENTRIES

DO $20 I=1, N C X$

DO $20 \mathrm{~J}=1, \mathrm{NC}$

$20 \mathrm{~A}(\mathrm{I}, \mathrm{J})=0.0 \mathrm{D} 0$

DO $21 \quad I=1, N S$

$D O 21 \mathrm{~J}=1, \mathrm{NC}$

$21 B(I, J)=0.000$

WRITE $(9, \star)$ ' YOU MUST NOW ENTER THE STOICHIOMETRIC MATRIX EOR' WRITE $(9, *)$ ' THE COMPLEXES ENTERED ABOVE'

WRITE $(9, \star)$ ' FOR EACH COMPLEX YOU WILL HAVE TO ENTER THE NUMBER'

WRITE $(9, *)$ ' OF COMPONENTS, THEN EACH COMPONENT NUMBER AND'

WRITE $(9, *)$ ' STOICHIOMETRIC COEFEICIENT'

DO $30 \quad I=1, N C X$

C....GET THE NUMBER OF COMPONENTS IN COMPLEX I

WRITE $(9, *)$ ' ENTER THE NUMBER OF COMPONENTS IN COMPLEX',

$\& I, 1, \operatorname{CMPLX}(I)$

$\operatorname{READ}(9, *) \operatorname{NCOMP}(I)$

DO $25 \mathrm{~J}=1, \operatorname{NCOMP}(I)$

WRITE $(9, *)$ ' ENTER THE NUMBER AND STOICHIOMETRIC COEFFICIENT OF'

WRITE $(9, *)$ ' COMPONENT', J,' OF ', CMPLX(I)

READ $(9, *)$ JCOMP, JSTOIC

C.... PUT DATA IN MATRIX A

$A(I, J C O M P)=J S T O I C$

25 CONTINUE

30 CONTINUE

WRITE $(9, *)$ ' YOU MUST NOW ENTER THE STOICHIOMETRIC MATRIX FOR'

WRITE $(9, *)$ ' THE PRECIPITATES ENTERED ABOVE FOR EACH.

WRITE $(9, *)$ ' PRECIPITATE YOU WILL HAVE TO ENTER THE NUMBER' 
WRITE $(9, *)$ ' OF COMPONENTS, THEN EACH COMPONENT NUMBER AND' WRIIE $(9, *)$ ' STOICHIOMETRIC COEFFICIENT'

DO $40 \mathrm{I}=1$, NS

C....GET THE NUMBER OF COMPONENTS IN PRECIPITATE I

WRITE $(9, *)$ ' ENTER THE NUMBER OF COMPONENTS IN PRECIPITATE',

SI, ' ', PPT (I)

$\operatorname{READ}(9, *) \operatorname{NPPT}(I)$

DO $35 \mathrm{~J}=1$, NPPT (I)

WRITE $(9, *)$ ' ENTER THE NUMBER AND STOICHIOMETRIC COEEFICIENT OE'

WRITE $(9, *)$ ' COMPONENT',J, ' OE ', PPT (I)

$\operatorname{READ}(9, *)$ JCOMP, JSTOIC

C.....PUT DATA IN MATRIX B

$B(I, J C O M P)=J S T O I C$

35 CONTINUE

40 CONTINUE

C.... INPUT TOTAL SOLUBLE COMPONENT CONCENTRATIONS AND INITIAL

C.... GUESSES FOR THE FREE COMPONENT CONCENTRATION AT EQUILIBRIUM DO $41 I=1, N C$

WRITE $(9, *)$ ' INPUT THE TOTAL SOLUBLE CONCENTRATION AND AN INITIAL WRITE $(9, *)$ ' GUESS FOR THE CONCENTRATION EOR COMPONENT',

$\& I, '$ ', $\operatorname{COMP}(I)$

$\operatorname{READ}(9, \star) U(I), C(I)$

41 CONTINUE

WRITE $(9, *)$ ' INPUT A " 1 " IE THE SOLUBILITY CONTRAINT SHOULD BE' WRITE $(9, *)$ ' CHECKED FOR THE INITIAL GUESS'

WRITE $(9, *)$ ' OR INPUT A "O" IF THE INITIAL GUESSES SHOULD BE' WRITE $(9, \star)$ ' USED TO FIRST CALCULATE THE BATCH EQUILIBRIUM' WRITE $(9, *)$ ' WITHOUT THE SOLID. THE SOLUBILITY CONSTRAINT" WRITE $(9, *)$, WILL THEN BE CHECKED AND ENFORCED IF NECESSARY $\operatorname{READ}(9, *)$ IBATCH

C.... END OF DATA INPUT FROM KEYBOARD, USE THIS DATA TO CREATE AN

C..... INPUT EILE. THE USER MAY THEN MODIFY DATA IN THE CREATED EILE

C.... AND CHOOSE DATA INPUT FROM FILE FOR OTHER TRIALS.

WRITE $(9, *)$ ' ENTER A FILE NAME TO STORE INPUT DATA'

$\operatorname{READ}(9, *)$ INDATA

OPEN $(8$, EILE-INDATA, STATUS = 'NEW' $)$

WRITE $(8,1000)$ TITLE

WRITE $(8, *)$ ALPHA, DELTA

WRITE $(8, *)$ NC, NCX, NS

C..... NAMES AND CONSTANTS

DO $42 I=1$, NC

42 WRITE $(8, \star)$ COMP (I)

DO $43 I=1, N C X$

43 WRITE $\left(8,{ }^{\star}\right)$ CMPLX (I), RK (I)

DO $44 I=1, N S$

$44 \operatorname{WRITE}(8, *) \operatorname{PPT}(\mathrm{I}), \operatorname{RKSO}(I)$

C.... STOICHIOMETRIC MATRICES

C..... COMPLEXES

DO $46 I-1, N C X$

WRITE $(8, *) \operatorname{NCOMP}(I)$

DO $45 \mathrm{~J}=1$, NC

$\operatorname{IE}(A(I, J)$.NE. $0.0 D 0)$ WRITE $(8, *) J, A(I, J)$

45 CONTINUE

46 CONTINUE

C.....PRECIPITATES

DO $48 \quad I=1$, NS

WRITE $(8, *) \operatorname{NPPT}(I)$

DO $47 \mathrm{~J}=1, \mathrm{NC}$

$\operatorname{IE}(B(I, J)$.NE. 0.000$)$ WRITE $(8, *) J, B(I, J)$

47 CONTINUE

48 CONTINUE

C.... TOTAL SOLUBLE COMPONENT CONCENTRATIONS AND INITIAL GUESSES DO $49 I=1$, NC

49 WRITE $(8, *) \cup(I), C(I)$

WRITE $(8, *)$ IBATCH

C

C.....END OF WRITING INPUT DATA TO EILE, SKIP NEXT SECTION WHICH

C.... READS INPUT DATA EROM A FILE

GO TO 100 
C

50 CONTINUE

C. . . READ INPUT DATA FROM A FILE

C.....GET DATA EILE NAME

WRITE $(9, *)$ ' ENTER THE NAME OF THE INPUT DATA FILE

$\operatorname{REAO}(9, *)$ INDATA

$\operatorname{OPEN}(8$, F ILE-INDATA, STATUS = ' OLD')

$\operatorname{READ}(8,1000)$ TITLE

$\operatorname{READ}(8, *)$ ALPHA, DELTA

$\operatorname{READ}(8, *) N C, N C X, N S$

C..... NAMES AND CONSTANTS

DO $51 \quad I=1$, NC

$51 \operatorname{READ}(8, *) \operatorname{COMP}(I)$

DO $52 I=1, N C X$

$52 \operatorname{READ}(8, *) \operatorname{CMPLX}(I), \operatorname{RK}(I)$

DO $60 \quad I=1, N S$

$60 \operatorname{READ}(8, \star) \operatorname{PPT}(I), \operatorname{RKSO}(I)$

C..... STOICHIOMETRIC MATRICES

C.... SET ALL ENTRIES TO ZERO

DO $65 I=1$, NCX

DO $65 \mathrm{~J}=1, \mathrm{NC}$

$65 A(I, J)=0.0 D 0$

DO $70 \quad I=1, N S$

DO $70 \mathrm{~J}=1, \mathrm{NC}$

$70 \mathrm{~B}(I, J)=0.000$

C. . . COMPLEXES

DO $86 \mathrm{I} I=1, \mathrm{NCX}$

$\operatorname{READ}(8, *) \operatorname{NCOMP}(I)$

DO $75 \mathrm{~J}=1, \operatorname{NCOMP}(I)$

$\operatorname{READ}(8$, *) JCOMP , JSTOIC

$A(I, J C O M P)=J S T O I C$

75 CONTINUE

80 CONTINUE

C.... PRECIPITATES

DO $90 \quad I=1$, NS

$\operatorname{READ}(8, *) \operatorname{NPPT}(I)$

DO $85 \mathrm{~J}=1$, NPPT (I)

READ $(8, *)$ JCOMP, JSTOIC

$B(I, J C O M P)=J S T O I C$

85 CONTINUE

90 CONTINUE

C.... TOTAL SOLUBLE COMPONENT CONCENTRATIONS AND INITIAL GUESSES DO $95 I=1, N C$

$95 \operatorname{READ}(8, *) \cup(I), C(I)$

$\operatorname{READ}(\theta, *)$ IBATCH

C

C.....END OF DATA INPUT SECTION

$\mathrm{C}$

100 CONTINUE

C.....BATCH EQUILIBRIUM PROGRAM

C

C.... SET OTHER NEEDED VARIABLES

ITERMAX $=50$

C.....INITIALIZE VARIABLES

DO $105 \quad I=1$, NC

DO $104 \mathrm{~J}=1, \mathrm{NC}$

$\operatorname{RLHS}(I, J)=0.0 D 0$

$D F(I, J)=0.0 D 0$

$D Q(I, J)=0.0 D 0$

104 CONTINUE

$F(I)=0.000$

$Q(I)=0.0 D O$

105 CONTINUE

C.... INITIALIZE ITERATION LOOP ITER $=1$

C. . . RETURN HERE EOR ITERATIONS

110 CONTINUE

C....EVALUATE $F(K)$ AND $d F(K) / d C(J)$ 


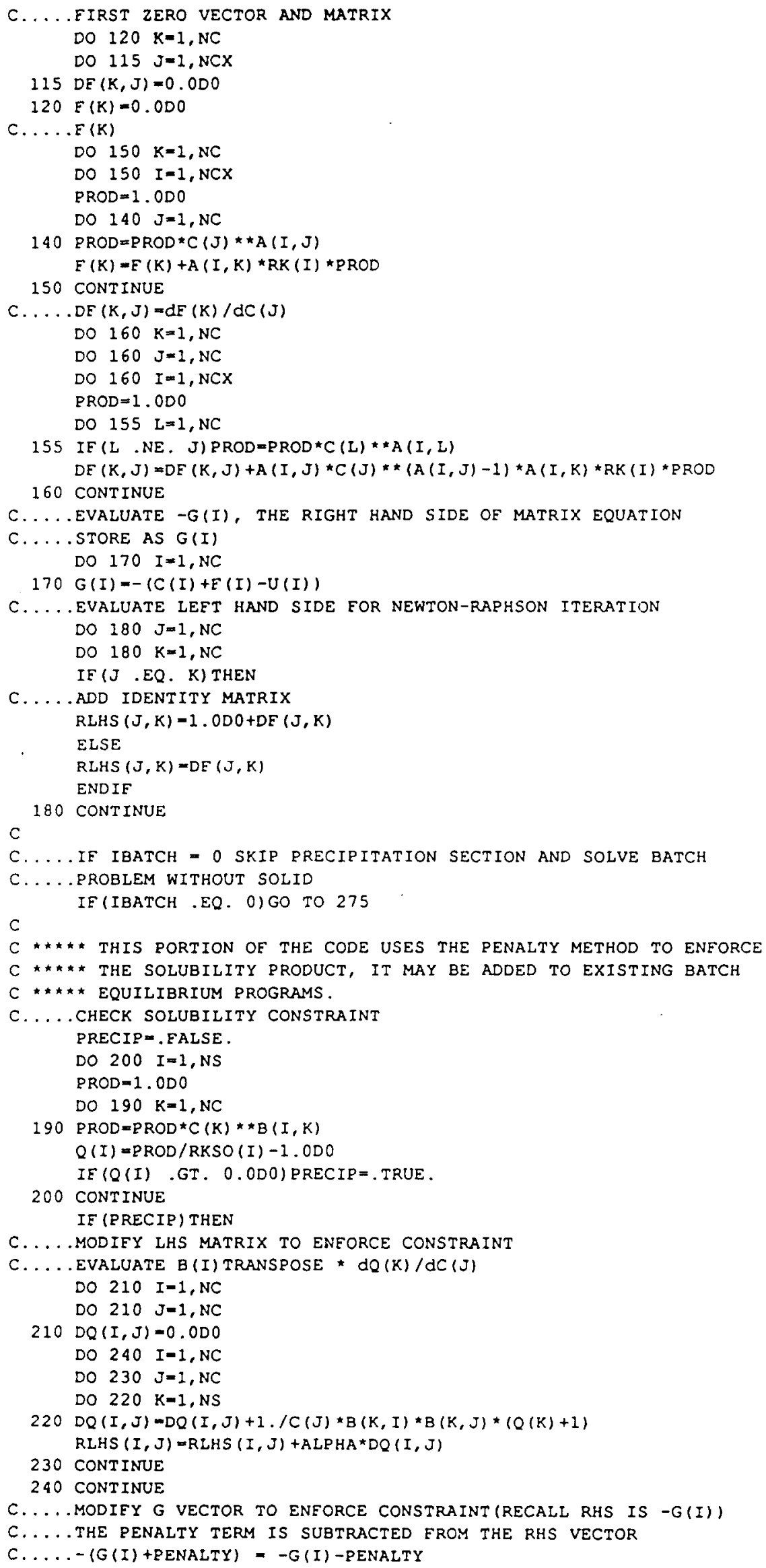




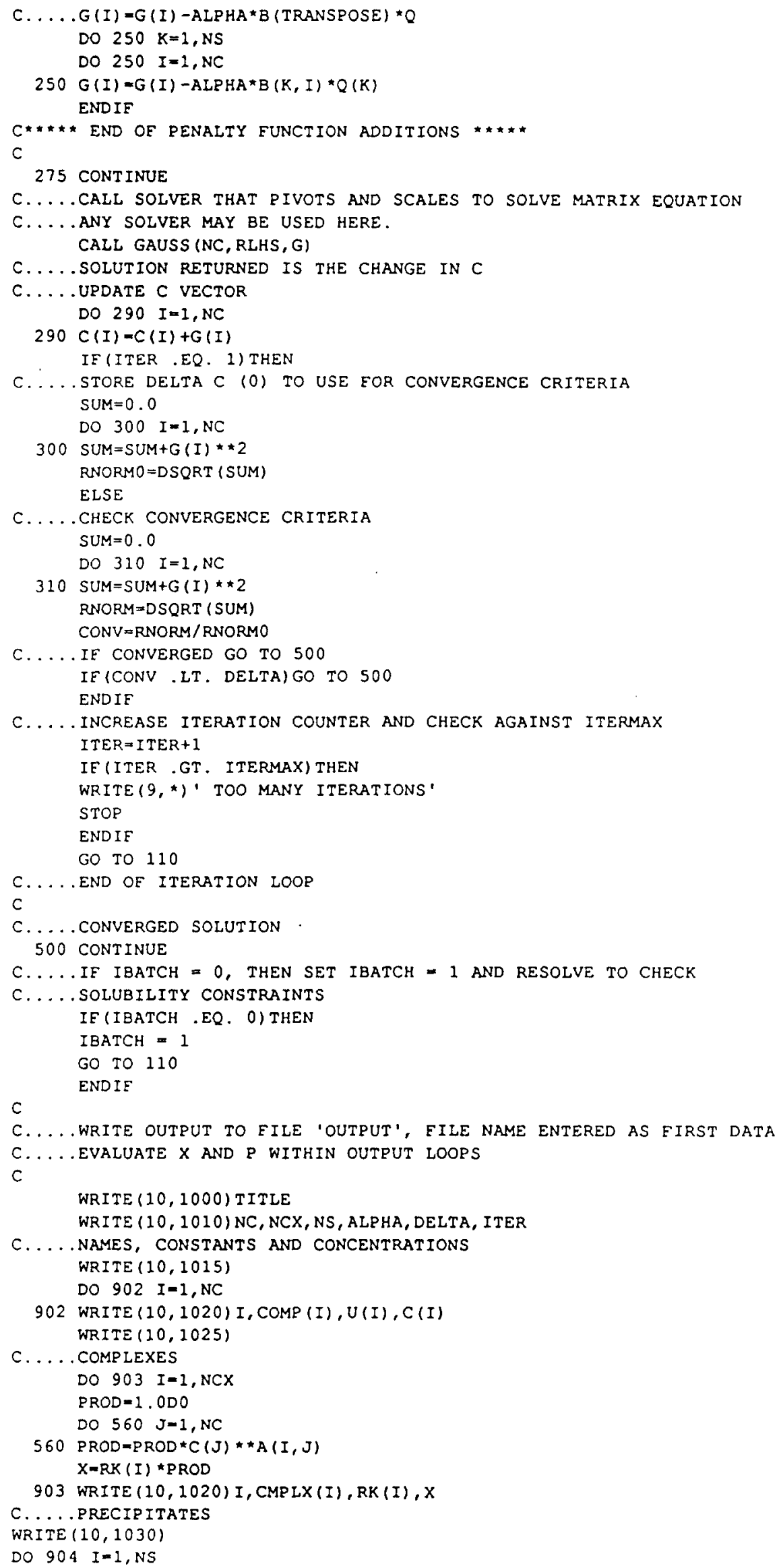


IF $(Q(I)$.GT. 0.000$)$ THEN

$P=A L P H A * Q(I)$

ELSE

$\mathrm{P}=0.000$

ENDIF

$904 \operatorname{WRITE}(10,1020) I, \operatorname{PPT}(I), \operatorname{RKSO}(I), P$

C....WRITE STOICHIOMETRIC MATRICES IN TABULAR FORM

C.... TABLES WITH EIGHT COMPONENTS ACROSS, ADDITIONAL TABLES ARE

C..... FORMED IF NC IS GREATER THAN EIGHT

C. . . . COMPLEXES

C.... SEE HOW MANY TABLES WILL BE NEEDED, ITABLE IS AN INTEGER

ITABLE $=\mathrm{NC} / 8+1$

ISTART $=1$

IF IN $=8$

WRITE $(10,1031)$

DO $910 K=1$, ITABLE

IF (K.EQ. ITABLE) IF IN $=N C$

WRITE $(10,1035)$ (COMP (II), I I =ISTART, IF IN)

DO $905 \mathrm{I}=1, \mathrm{NCX}$

$\operatorname{WRITE}(10,1040) I, \operatorname{CMPLX}(I),(A(I, J), J=I S T A R T, \operatorname{IEIN})$

905 CONTINUE

ISTART $=$ ISTART +8

IF IN $=$ IF IN +8

910 CONTINUE

C....PRECIPITATES

ISTART $=1$

IF IN $=8$

WRITE $(10,1032)$

DO $920 \mathrm{~K}=1$, ITABLE

IF (K .EQ. ITABLE) IF IN=NC

WRITE $(10,1036)$ (COMP (II), I I=ISTART, IE IN)

DO $915 I=1$, NS

WRITE $(10,1040) I, P P T(I),(B(I, J), J=I S T A R T, I F I N)$

915 CONTINUE

ISTART $=I S T A R T+8$

IF IN $=$ IF IN +8

920 CONTINUE

C.... CLOSE FILES

CLOSE (8)

CLOSE (10)

C..... EORMAT STATEMENTS

1000 FORMAT (20A4)

1010 FORMAT (/5X, 'NUMBER OF COMPONENTS', 10X, I3, /, 5X,

1 'NUMBER OF COMPLEXES', $11 \mathrm{X}, 13,1,5 \mathrm{X}$, 'NUMBER OF PRECIPITATES',

$28 \mathrm{X}, \mathrm{I} 3,1 /, 5 \mathrm{X}$, 'PENALTY PARAMETER', 15X, E10.4, /, 5X,

3 'CONVERGENCE CRITERIA', 12X, E10.4, $1,5 \mathrm{X}$,

4 'NUMBER OF ITERAT IONS USED', 6X, I2)

1015 FORMAT (/5X, 'COMPONENT', 10X, 'NAME', 10X,

1 'TOTAL SOLUBLE CONCENTRATION', 5X, 'CONCENTRATION')

1020 FORMAT (7X, I 3, 15X, A8, 10X, G10.4, 20X, G10.4)

1025 EORMAT (/6X, 'COMPLEX', 11X, 'NAME', 12X, 'EQUILIBRIUM CONSTANT', $110 \mathrm{X}$, 'CONCENTRATION')

1030 FORMAT (/4X, 'PRECIPITATE', 9X, 'NAME', 12X, 'SOLUBILITY PRODUCT', $112 \mathrm{X}$, 'CONCENTRATION'।

1031 FORMAT (//20X, 'STOICHIOMETRIC COEFFICIENTS FOR COMPLEXES', $/$,

$140 \mathrm{X}$, 'COMPONENTS')

1032 FORMAT (//20X, 'STOICHIOMETRIC COEFEICIENTS FOR PRECIPITATES',

$1 /, 40 \mathrm{X}$, 'COMPONENTS',

1035 FORMAT ( $6 \mathrm{X}$, 'COMPLEX', $8 \mathrm{X}$, 'NAME', $3 \mathrm{X}, 8(2 \mathrm{X}, \mathrm{A} 8)$ )

1036 FORMAT ( $4 X$, 'PRECIPITATE', $6 \mathrm{X}$, 'NAME' $, 3 X, 8(2 \mathrm{X}, \mathrm{A} 8)$ )

1040 EORMAT $(7 X, I 3,10 X, A B, 2 X, 8(I 2,8 X))$

STOP

END

SUBROUTINE GAUSS (NEO, A, F)

C.... SUBROUTINE TO PERFORM GAUSS ELIMINATION ON THE MATRIX EQUATION

$C . . . A * X=E$. THE SOLUTION IS RETURNED IN THE LOADING

C....VVECTOR $F$, NEQ IS THE NUMBER OF EQUATIONS. THE DIMENSIONS OF $F$

C.... AND A MUST MATCH THOSE IN THE CALLING PROGRAM.

C.... ADARTED EROM NAIVE GAUSS ELIMINATION PROGRAM FROM 


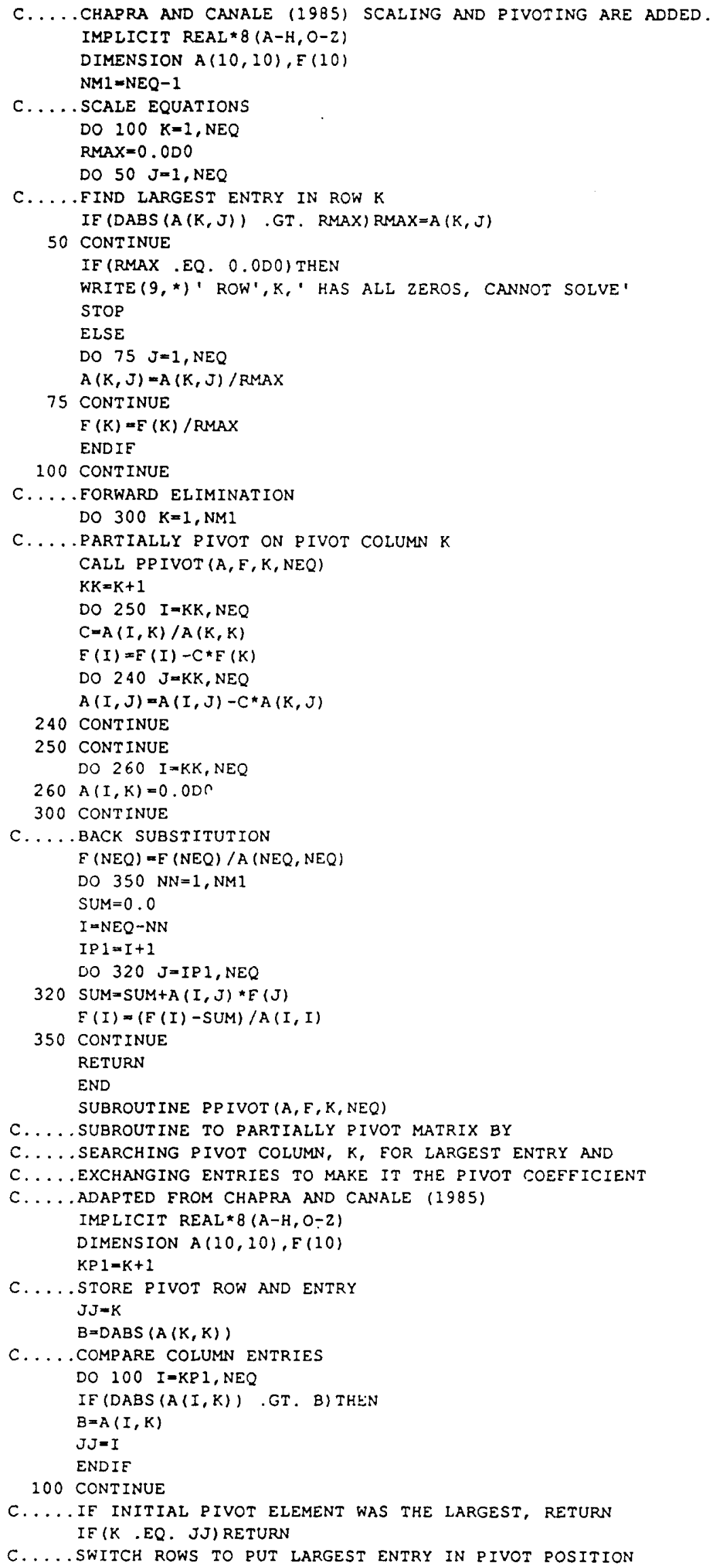




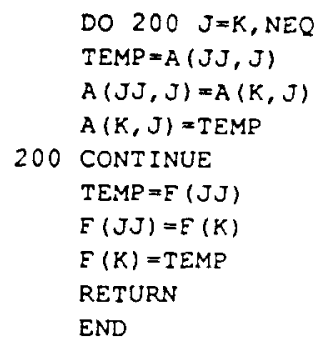

Example Problem 1--Input

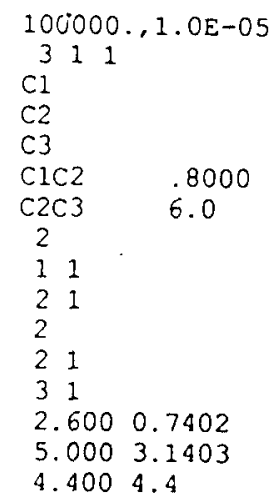

Example Proble'm 1-Oulput

NUMBER OF COMPONENTS NUMBER OF COMPLEXES

NUMBER OF PRECIPITATES PENALTY PARAMETER

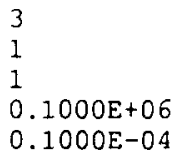

TOTAL SOLUBLE CONCENTRATION 2.600
5.000
4.400

EQUILIBRIUM CONSTANI .8000

SOLUBILITY PRODUCT 6.000
CONCENTRATION

1.000

2.000

3.000

CONCENTRATION 1.600

CONCENTRATION 1.400

STOICHIOMETRIC COEFFICIENTS FOR COMPLEXES

\begin{tabular}{ccrrr} 
COMPLEX & NAME & $\mathrm{Cl}$ & \multicolumn{2}{c}{ COMPONENTS } \\
1 & $\mathrm{ClC} 2$ & 1 & 1 & 0
\end{tabular}

STOICHIOMETRIC COEFFICIENTS FOR PRECIPITATES

\begin{tabular}{ccccc} 
& \multicolumn{3}{c}{ COMPONENTS } \\
PRECIPITATE & NAME & $\mathrm{Cl}$ & $\mathrm{C} 2$ & $\mathrm{C} 3$ \\
1 & $\mathrm{C} 2 \mathrm{C} 3$ & 0 & 1 & 1
\end{tabular}

NUMBER OF COMPONENTS

NUMBER OF COMPLEXES

NUMBER OF PRECIPITATES

PENALTY PARAMETER

CONVERGENCE CRITIRIA

NUMBER OF ITERATIONS USED

3

1

$0.1000 E+06$

$0.1000 E-04$

10 


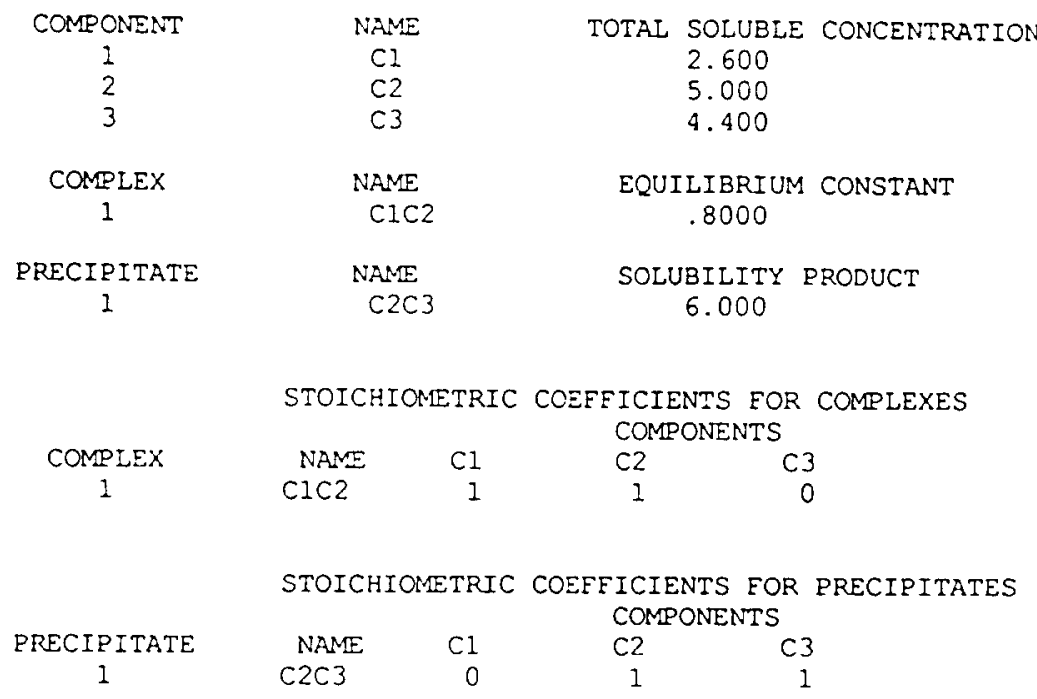

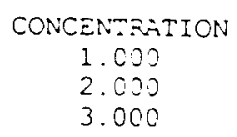

CONCENTEATION 1.400

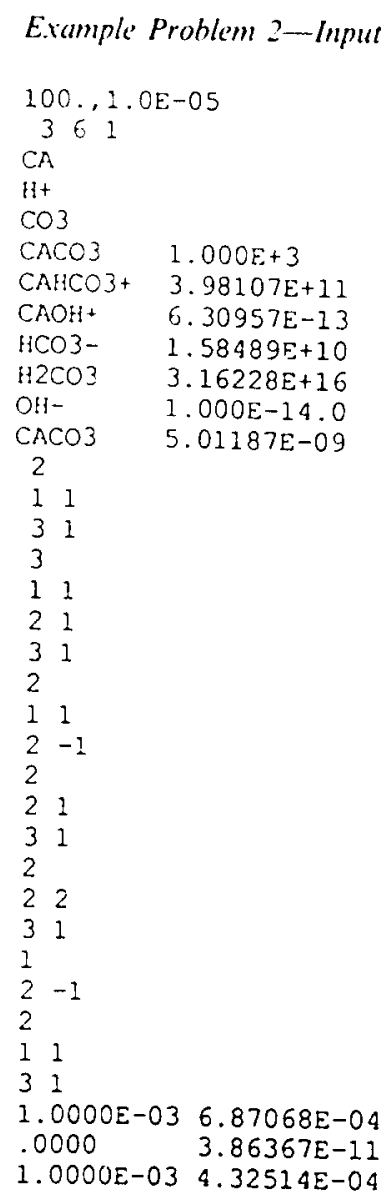

Example Problem 2-Output

NUMBER OF COMPONENTS

NUMBER OF COMPLEXES

NUMBER OF PRECIPITATES

PENALTY PARAMETER

6

CONVERGENCE CRITERIA

NUMBER OF ITERATIONS USED

$0.1000 E+03$

$0.1000 E-04$

COMPONENT

NAME 
40

D. J. KiRK.Ner and H. W, ReEves

2

3

COMPLEX

1

2

3

4

5

PRECIPITATE

1

$\mathrm{H}+$

$\mathrm{CO} 3$

NAME

$\mathrm{CACO} 3$

CAHCO $3+$

$\mathrm{CAOH}+$

$\mathrm{HCO} 3-$

$\mathrm{H} 2 \mathrm{CO} 3$

$\mathrm{OH}-$

NAME

$\mathrm{CACO} 3$
.0000

$0.1000 E-02$

EQUILIBRIUM CONSTANT

$$
1000 .
$$

$0.3981 E+12$

$0.6310 E-12$

$0.1585 \mathrm{E}+11$

$0.3162 E+17$

$0.1000 \mathrm{E}-13$

SOLUBILITY PRODUCT

$0.5012 E-08$
$0.1240 E-09$

$0.4122 E-04$

CONCENTRATION

$0.5012 E-05$

$0.2474 E-06$

$0.6188 \mathrm{E}-06$

$0.8099 \mathrm{E}-04$

$0.2003 \mathrm{E}-07$

$0.8066 E-04$

CONCENTRATION $0.8327 E-03$

STOICHIOMETRIC COEFEICIENTS FOR COMPLEXES

\begin{tabular}{clrrc} 
& & \multicolumn{3}{c}{ COMPONENTS } \\
COMPLEX & NAME & CA & H+ & CO3 \\
1 & CACO3 & 1 & 0 & 1 \\
2 & CAHCO3+ & 1 & 1 & 1 \\
3 & CAOH+ & 1 & -1 & 0 \\
4 & HCO3- & 0 & 1 & 1 \\
5 & H2CO3 & 0 & 2 & 1 \\
6 & OH- & 0 & -1 & 0
\end{tabular}

STOICHIOMETRIC COEFEICIENTS FOR PRECIPITATES

$\begin{array}{ccccc}\text { PRECIPITATE } & \text { NAME } & \text { CA } & \text { H+ } & \text { CO3 } \\ 1 & \text { CACO3 } & 1 & 0 & 1\end{array}$

